\title{
Charcot-Marie-Tooth Disease Type 1A
}

National Cancer Institute

\section{Source}

National Cancer Institute. Charcot-Marie-Tooth Disease Type 1A. NCI Thesaurus. Code C75468.

Charcot-Marie-T ooth disease caused by mutations in the PMP22 gene (mapped to chromosome 17), resulting in peripheral nerve demyelination. 